\title{
INVESTIGATION OF PRESERVICE TEACHERS' PROBLEM SOLVING STRATEGIES IN COMPUTER ALGEBRA SYSTEMS ENVIRONMENTS
}

\author{
Yasemin SAĞLAM* \\ Arif ALTUN** \\ Petek AŞKAR ${ }^{* * *}$
}

\begin{abstract}
The purpose of the study was to investigate undergraduate students' problem solving strategies in a computer software envoriment. The participants of this study consist of three male and two female students attending Computer Programming II course in a mathematics teacher training program during the Spring Semester of 2006-2007. In this study, data were collected through clinical interviews, semi structered interviews and observations. Data were analyzed using content analysis by Nvivo7. According to study findings, most frequently used strategy by the students are decomposing and simplifying, analogy, anti looping strategy and means-end analysis at Maple.
\end{abstract}

Key Words: Computer algebra systems, problem solving strategies, mathematics education

\footnotetext{
* Res. Assist., Hacettepe University, Faculty of Education, ysaglam@ hacettepe.edu.tr ** Assoc. Prof. Dr., Hacettepe University, Faculty of Education, altunar@ hacettepe.edu.tr ${ }^{* * * *}$ Prof.Dr., Hacettepe University, Faculty of Education, paskar@ hacettepe.edu.tr
} 


\section{SUMMARY}

Purpose and Significance: The purpose of this study was to investigate undergraduate students' problem solving strategies in a computer algebra system. The literature about problem solving strategies has been focused mostly on age, difficulty of the problem, cognitive dimension of the strategies and novice-expert comparisions. As to the studies with computers, problem situation has been analyzed independently from the computer environment and the effects of computer software on problem solving strategies hasn't been investigated. Maple, as a computer algebra system, is a computer software mainly used in mathematics and engineering to solve problems. In the field of mathematics education, Maple is mainly used to teach certain concepts like limit (Kabaca, 2006), derivative (Aksoy, 2007), applications of derivative (Bulut, 2009) and definite integral (Aktümen, 2007). Computer based environments that enable users to express their problems in mathematical terms can be referred as problem solving environments (Houstis, 2003). Therefore, this study was designed to analyse university students' problem solving strategies at Maple environment.

Method: The participants of this study included three male and two female students attending Computer Programming II course in a mathematics teacher training program during the Spring Semester of 20062007. Two of these students were described as high achiever, one of them as medium achiever and the others low achievers by the classroom instructor. Clinical interviews were conducted with high and medium achievers. Also data were collected from semi structered interviews with all participants and clasroom observations were conducted at the begining of the study. All interviews were videotaped and transcribed by the researcher. Data were analyzed using content analysis by Nvivo7. To investigate students' problem solving strategies, a two-stage problem were used. The criteria to choose these problems were adequacy of mathematical difficulty level, instructor's recommendations and command knowledge of the students.

Results: According to the study findings, most frequently used strategy by the students are decomposing and simplifying, anti-looping strategy, analogy and means-ends analysis at Maple. Control strategies used by students are re-read the problem, re-read the procedure, check calculations and check the plan. Reaching the correct solution for a given problem is found to be highly related to applying another new strategy after checking. While more advanced strategies like decomposing and analogy carried the high achiever students to the correct solution, the less advanced strategy trial and eror- used by medium achiever student was unsatisfactory. 
Conclusions: In recent years, the software programs such as Computer Algebra Systems (CAS) have been placed at the heart of mathematics and mathematics education. Researchers claim that the use of the software programs bring both negative and positive effects on mathematics learning because it highly depends on the appropriate use of the software. Using a program such as CAS, if used approriately, will provide opportunities for students to benefit from computing characteristics of CAS environments during problem solving which paper-pencil can't provide. Thus, when designing instructional activities in line with the curricula, it should be kept in mind that such integration of CAS into mathematics would be beneficial for students in order to help them develop more effective strategies. But the success of a curriculum like this depends on the experienced mathematics teachers. Therefore it will be useful to support the mathematics teacher training programs in universities with current softwares like Maple. Further improvements to these systems would also be a challenge for instructional designers. 


\title{
BÍLGISSAYAR CEBİRI SISTEMLERİ ORTAMLARINDA ÖĞRETMEN ADAYLARININ PROBLEM ÇÖZME STRATEJILERINIIN İNCELENMESI
}

\author{
Yasemin SAĞLAM* \\ Arif ALTUN** \\ Petek AŞKAR ${ }^{* * *}$
}

ÖZ: $\mathrm{Bu}$ çalışmanın amacı, üniversite öğrencilerinin problem çözme stratejilerini bir bilgisayar yazılımı ortamında incelemektir. Çalışmaya, Matematik Öğretmenliği, II. Sınıfinda eğitim gören ve 2006-2007 Bahar Dönemi içinde bilgisayar programlama dersine devam eden üç erkek ve iki kız öğrenci dahil edilmiştir. Veri toplama yöntemi olarak klinik, yarı-yapılandırılmış görüşme ve katılımcı gözlem teknikleri kullanılmıştır. Toplanan veriler, içerik analizi kullanılarak Nvivo7 programında analiz edilmiştir. Araştırma sonuçlarına göre öğrencilerin Maple'da problem çözmek için en sık kullandığı stratejiler ayrıştırma ve sadeleştirme, benzer problem bulma döngüsel olmayan strateji ile araç amaç analizi olarak belirlenmiştir.

Anahtar Sözcükler: Bilgisayar cebiri sistemleri, problem çözme stratejileri, matematik eğitimi

\footnotetext{
* Araş. Gör., Hacettepe Üniversitesi Eğitim Fakültesi OFMA Eğitimi Bölümü ysaglam@hacettepe.edu.tr

*** Doç. Dr., Hacettepe Üniversitesi Eğitim Fakültesi Bilgisayar ve Öğretim Teknolojileri Eğitimi Bölümü altunar@hacettepe.edu.tr

Prof. Dr., Hacettepe Üniversitesi Eğitim Fakültesi Bilgisayar ve Öğretim Teknolojileri

Eğitimi Bölümü paskar@hacettepe.edu.tr
} 


\section{GÍRIŞ}

Problem çözme ile ilgili olarak birçok araştırma yapılmış ve buna bağlı olarak da birçok araştırmacı tarafindan problem ve problem çözmeye dair çeşitli tanımlar ortaya konmuştur. Yapılan problem tanımları incelendiğinde görülmektedir ki problem, bireyin daha önce karşılaşmadığ1 ve çözmek istediği durum (Altun, 2000) olarak tanımlanırken; problem çözme ise yeni bir bilgi kazanmak için var olan bilgilerin yeni bir alana uygulanması olarak tanımlanabilir (Sternberg, 1995; Killen, 1996; akt. Hammouri, 2003).

Problem çözme stratejileri ise genel olarak, problem çözme sürecinde rehberlik yapan fakat doğru sonuç konusunda garanti vermeyen teknikler olarak karşımıza çıkmaktadır (Mayer, 1983, s.374). Problem çözme stratejileriyle ilgili ilk tartışmaların Pólya (1945)'nın “Nasıl Çözmeli?”(How to solve it?) adlı kitabına dayandığı söylenebilir. Bu kitapta, problem çözme süreci dört farklı basamakta ifade edilmiş ve her bir basamakta kullanılabilecek problem çözme stratejilerine örnekler verilmiştir.

Pólya'nın belirttiği stratejilerin yanında, alanyazında da çeşitli problem çözme stratejileri tanımlanmıştır: (1) Bir önceki aşamada yapılanların, mevcut aşamada yapılacakların kontrolünü sağladığı, böylece bir önceki aşamaya dönmeyi engelleyen, döngüsel olmayan strateji (anti looping heuristic) (Davies, 2000); (2) Mevcut durumla, problemin amacı arasındaki fark1 en aza indirme stratejilerini içeren araç-amaç analizi (Reed, 2007); (3) Bir resim veya şekil çimek, tablo veya liste oluşturmak (Malloy, Jones, 1998) (4) Problemin parçaları yerine bütününe odaklanılan holistik strateji ile sonuca ulaşmaya çalışırken, problemin birbirinden farklı parçalarını düşünülmesini içeren analitik strateji (Boulter \& Kirby, 1994; Malloy \& Jones, 1998); (5) Benzer problemleri kullanarak çözme (Reed, 2007); (6) Birdenbire ortaya çıkan sonucu doğrulama (pop-upverify)(Hammouri,2003); (7) Bireylerin, tamamıla tanıdık olmayan bir problem durumuyla birdenbire karşılaştıklarında ve çözüme dair herhangi bir planları olmadığında probleme başlamak için kullandıkları deneme yanılma stratejisi.(Brunning, Schraw \&Ronnig,1995); (8) Olası çözümleri üretme ve doğruluğunu test etme (Jonassen, 1997), (9) Ayrıştırma ve sadeleştirme (Jonassen, 1997).

Problem çözme her ne kadar geniş bir anlama sahip olsa da problem çözme dendiği zaman akla daha çok matematiksel problem çözme gelmiş ve buna paralel olarak da problem çözme stratejileri üzerine yapılan araştırmalar, daha çok matematiksel problemler üzerinde yoğunlaşmıştır. Harmon ve Morse (1995) çalışmalarında, problem çözme stratejileri ile yapılan araştırmaları bir araya getirmişlerdir. Bu çalışmada, bilgi ve problem 
çözme stratejisi arasındaki ilişkiyi, strateji seçimini etkileyen faktörleri, uzmanlık düzeyinin etkisini ve bilgiden bağımsız olarak strateji kullanımının etkilerini inceleyen makaleler özetlenmiştir. Gorgorió (1998) da çalışmasında, 12- 16 yaşındaki öğrencilerin, uzamsal döndürme gerektiren geometri problemlerdeki bilişsel stratejilerini tanımlamış ve bu stratejileri yapısal, işlemsel ve yaklaşma boyutunda incelemiştir. Kullanılan stratejilerde ise farkın oluştuğu durumların görev yapısından kaynakladığı sonucuna ulaşmıştır.

Hammouri (2003) de üniversite öğrencilerinin kullandığı problem çözme stratejilerini belirlemek için bir geometri problemiyle Hanoi Kulesi problemini kullanmış; ayrıca bu araştırmada bilişsel ve biliş ötesi süreçlerin, holistik ve analitik strateji kullanımını tahmin edip etmediğini de araştırmıştır. Çalışma sonucunda ise ögrencilerin dokuz tane strateji (döngüsel strateji ileri doğru planlama, döngüsel strateji geriye doğru planlama, araç amaç analizi ileri doğru planlama, araç amaç analizi geriye doğru planlama, benzer bir problemi hatırlama, genelleme ve test etme, deneme yanılma, birdenbire ortaya çıkan sonucu doğrulama) kullandığını gözlemlemiştir. Ayrıca problemi anlama ve kontrol etme, holistik stratejinin; planlama ve öz düzenleme ise analitik stratejinin kullanımında önemli bir yordayıcı olarak rol aldığ 1 belirtilmektedir.

Problem çözme stratejileri ile ilgili yapılan araştırmalar genellikle yaş, problemin zorluk düzeyi ve bilişsel boyutta ele alınmış, acemi-uzman karşılaştırmaları yapılmıştır. Bilgisayar ortamında yapılan çalışmalarda da problem durumu, ortamdan bağımsız olarak incelenmiş, farklı ortamların ya da yazılımların problem çözme stratejilerini nasıl değiştirdiği araştırılmamıştır. Bu yüzden bu çalışmanın amacı, öğretmen adaylarının bir Bilgisayar Cebiri Sistemi olan Maple'da, problem çözmek için kullandıkları stratejilerin neler olduğunu araştırmaktır.

\section{Bilgisayar Cebiri Sistemleri ve Maple}

Bilişim teknolojisine paralel olarak ilerleyen bilgisayar teknolojisi, çeşitli yazılım ve programlarla her geçen gün hayatımızın daha fazla alanında yer almaya başlamıştır. Matematik ve matematik eğitimi de bu alanlar arasında yer almaktadır. Sayısal ve sembolik işlemleri veya birkaç değişkenli fonksiyonların çizimi gibi matematiksel işlemleri yapmak amacıyla geliştirilen matematiksel yazılımlar, matematik ve matematikle ilgili alanlarda artan bir oranda kullanılmaktadır. Bilgisayar Cebiri Sistemleri (BCS) de bu yazılımlar arasında önemli bir yer tutmaktadır. BCS, yukarıda sayılan işlemleri yapmakta kullanılan yazılımlar için ortak bir isimdir ve bunlar içerisinde en çok bilinen ve kullanılanları Derive, Theorist, Converge, Mathcad, Mathematica, MatLab, Maple'dır. 
BCS'nin matematik ve matematik eğitiminde kullanımı birçok araştırmaya konu olmuştur. $\mathrm{Bu}$ çalışmaların çoğunda, matematiksel bir konunun veya matematiksel bazı kavramların (limit, türev, integral vb.) öğrenilmesinde bilgisayar cebiri sistemlerinin etkinliğgi araştırılmıştır. Örneğin Kabaca (2006) limit, Aksoy (2007) türev, Bulut (2009) türev uygulamaları ve Aktümen (2007) belirli integral kavramının öğretilmesinde bilgisayar cebiri sistemlerinden Maple kullanımının etkilerini incelemiştir.

Bilgisayar yazılımlarının, problem çözme ve matematik öğrenimindeki etkinliğini, bilgisayar tabanlı dersler, programlama ve araçlar bağlamında inceleyen araştırmaları bir araya getiren McCoy (1996), BCS gibi bilgisayar tabanlı materyallerin, öğrenenlerin matematik başarısına yardımcı olmada etkili araçlar olduğunu belirtmektedir.

Cheung (1996), Maple'ın klasik sayı teorisi dersindeki kavram, teorem ve algoritmaların öğrenilmesini arttırmada nasıl kullanılabileceğini tartışırken, Stenphens ve Konvalina (1999) Maple'ın dahil edildiği kolej cebir derslerindeki öğrenci performans değişimini araştırmıştır. Araştırma sonucunda Maple' in dahil edilmesiyle elde edilen fark istatistiksel olarak anlamlı bulunmazken, öğrencilerin derse karşı tutumu olumlu yönde etkilenmiştir. Weigand ve Weller (2001) ise 11. sınıf öğrencilerinin bilgisayar cebiri (Derive, Mathplus veya Theorist) ortamında nasil çalıştıklarını, geleneksel kağıt-kalem kullanımıyla karşılaştırıldığında çalışma stillerinin nasıl değiştiğini, bilgisayar cebiri sistemleri ile çalışmanın fonksiyon kavramını anlamadaki başarıyı nasıl etkilediğini inceledikleri çalışmalarında, bilgisayarla çalışan grubun daha fazla gösterim kullandıklarını ve bu gösterimler arasında sı sık hareket ettiklerini (window-shuttle-principle) gözlemlerken, bilgisayar cebiri ile çalışmanın fonksiyon kavramını anlamadaki başarıya daha fazla katkı sağlamadığını fakat kağıt kalemle çalışan öğrencilere göre bu kavramı daha farklı şekilde anladıklarını gözlemlemişlerdir.

Ayrıca ekrandaki grafiğin öğrencilere, bir sonraki adım için başlangıç noktasi oluşturduğunu belirtmektedirler. Crocker (1991) ise analiz dersi kapsamında, BCS'nin (Mathematica) kullanımıyla öğrencilerin kavram gelişimlerini ve problem çözme becerilerini incelediği çalıșmasında, öğrencilerin problem çözme konusundaki cevaplarını dört kategoride toplamıştır: a) Cevabın olmaması b) Tek stratejiyle yapılan çözümler c) Çoklu stratejinin kullanıldığı fakat doğru cevaba ulaşılamayan çözümler d) Çoklu strateji kullanıp doğru cevaba ulaşılan çözümler. Ayrıca çözüm sürecinde bazı öğrencilerin bilgisayar ortamında çözüme başlamadan önce problem çözme stratejilerini planlarken, bazı öğrencilerin doğrudan bilgisayar ortamında çözüme başladıklarını, ortaya çıkan çözümü kabul ettiklerini ve eğer çözüme ulaşamazlarsa akıllarının karıştığını gözlemlemiştir. Pierce ve Stacey (2001) de üniversite öğrencilerinin analize 
giriş dersinde bilgisayar cebiri sistemlerinden biri olan Derive'in kullanılmasına ilişkin yorumlarını inceledikleri araştırmalarında, bu teknolojinin kullanımının bazı öğrenme stratejilerini tetiklediğine dair bulgular elde etmişlerdir. Görüldüğü gibi bilgisayar yazılımlarının öğrenme ortamı olarak kullanılmaya başlanması, bu ortamdaki öğrenci davranışlarının araştırılmasını önemli hale getirmektedir.

BCS'nden biri olan Maple ile yapılan araştırmaların bir kısmında ise matematik, fizik, mühendislik gibi alanlardaki problemlerin çözümünde ve matris tersi, Schur fonksiyonları, lineer cebir gibi çeşitli konuların uygulamalarında Maple'ın nasıl kullanıldı̆̆ (Gander \& Gruntz, 1992; Brody \& Rosenfield, 1996; Arsham \& Oblak, 1996; Srinivasan, 1997; Lu \& Ye, 2000; Carvalho \& D'Agostino, 2001; Ghusayni, 2004) ifade edilmiştir.

Ülkemizde de yeniden yapılandırılan ortaöğretim matematik dersi öğretim programında, BCS'nin matematik öğrenimi ve öğretimindeki rolüne doğrudan yer verilmektedir. Bu programda, BCS'nin problem çözme sürecindeki karmaşık işlem yükünü azaltarak, öğrencilere farklı koşullar altında işlem yapma olanağ 1 sağladığ işlemsel ve kavramsal ilişkileri gözlemleme firsatı buldukları belirtilmektedir (MEB, Ortaöğretim Matematik Dersi Öğretim Programı, 2005).

Araştırmacılar, BCS'nin öğrenme-öğretme sürecinde önemli bir araç olduğunu ve uygun kullanımının öğrencilerin kavramsal anlamalarını, problem çözme ve matematiksel becerilerini yükselteceğini belirtmektedirler (Leinbach, Pountney ve Etchells, 2002; Waters, 2003). Fakat bu süreçte göz ardı edilmemesi gereken en önemli nokta, BCS'nin değerlendirme sürecine girmediği takdirde matematik müfredatındaki etkisinin minimum düzeyde kalacağıdır (Pountney, Leinbach ve Etchells, 2002).

Ögrencilere, problemlerini matematiksel terimlerle ifade etme ve gerekli çözme bilgisiyle birleştirme olanağl sunan bilgisayar tabanlı ögrenme ortamlarl, aynı zamanda bir problem çözme ortamı olarak ifade edilebilir (Houstis, 2003).

Geçmişte, teknolojiyi de içine alan problem çözme araştırmaları programlama ile oldukça ilgilenmiştir. Bu araştırma siklıkla neticesiz olmuştur. Aslında matematiksel bir işlemi gerçekleştirecek bir bilgisayar programı yazmak heyecan verici olacaktır ve programcilarin kullanılan matematik yöntemleri hakkındaki algılarını güçlendirecektir. Fakat odaklanma matematiksel problemleri çözen programlar yerine programlama becerileri üzerinedir. Matematik bilimi içerisinde programlama için yer vardir, ama odak matematiksel problemler ve bilgisayarın bu problemleri çözmede araç olarak kullanılması olmalıdir (Wilson, Fernandez ve Hadaway: 1993). 


\section{YÖNTEM}

\section{Katılımcilar}

Çalışmada amaçlı örneklem kullanılmıştır. Amaçlı örneklemin kullanılmas1, zengin bilgiye sahip olan durumların derinlemesine çalışılmasına imkân sağlamaktadır; böylece çalışmanın odaklandığı sorular daha iyi aydınlanacaktır (Patton, 2002). Bu amaçla çalışmaya katılmak üzere Matematik Öğretmenliği, II. sınıfta eğitim gören ve 2006-2007 Bahar Dönemi içinde bilgisayar programlama dersine devam eden beş öğrenci belirlenmiştir. Yaş ortalaması 20 olan bu grupta, üç erkek ve iki kız öğrenci bulunmaktadır. Çalışmada yer alan öğrencilerden ikisi ders öğretmeninin tavsiyeleri dikkate alınarak derse karşı ilgili ve başarılı öğrenciler arasından seçilirken, diğer üç öğrenci araştırmacı tarafindan, araştırmaya gönüllü olarak katılmak isteyen öğrenciler arasından seçilmiştir. Seçilen beş öğrenciyle birer, yarı yapılandırılmış görüşme yapıldıktan sonra klinik görüşmelerle çalışmaya asıl veri kaynağı olan üç öğrenci belirlenmiştir.

Çalışmada kullanılan isimler öğrencilerin gerçek isimleri olmayıp, araştırma kapsamında verilen isimlerdir.

\section{Problem Seçimi}

Çalışmada iki aşamalı bir problem kullanılmıştır. İlk aşamada öğrencilerden, sorunun bir parçası olarak verilen matematiksel tanıma uygun bir prosedür (proc komutu) yazmaları beklenmektedir. İkinci aşamada ise birinci aşamada hazırladıkları prosedürü kullanarak matematiksel bir problemi çözmeleri istenmiştir. Problem seçilirken alan eğitimi uzmanından görüş alınmış ve problemin, öğrencilerin bilgi seviyesine uygun olmas1 göz önünde bulundurulmuştur. Çalışmada kullanılan problem şöyledir:

Tanım: $\mathrm{y}=\mathrm{f}(\mathrm{x})$ ile $\mathrm{y}=\mathrm{g}(\mathrm{x})$ fonksiyonlarının kesiştikleri $\left(\mathrm{x}_{0}, \mathrm{y}_{0}\right)$ gibi bir noktada, bu iki eğri arasında kalan açı, söz konusu noktada eğrilere çizilen teğetler arasındaki dar açı olarak tanımlanır.

1. Girilen iki eğri için bu eğriler arasında kalan açının tanjantını veren bir prosedür hazırlayınız.

2. Yukarıdaki prosedürü kullanarak $y=x^{2}-1$ ve $y=-x^{2}-7 x-7$ eğrileri arasındaki açının tanjantını bulunuz.

\section{Veri Toplama Süreci}

İlk aşamada araştırmacı, 2006-2007 Bahar Dönemi başından itibaren, içinde katılımcıların da bulunduğu sınıfla birlikte Maple'ın anlatıldığı Bilgisayar Programlama dersini dinlemeye başlamıştır. Ders, iki saat teorik 
ve iki saat uygulama şeklinde yürütülmektedir. Teorik derslerde Maple komutları öğrencilere tanıtılmakta, işleyişi hakkında bilgi verilmekte; uygulama kısmında ise teorik derste öğrenilen komutlara ilişkin bilgisayar laboratuarında çalışmalar yapılmaktadır. Temel komutların anlatımı sırasında, ikisi teorik, biri de uygulama sınıfında olmak üzere araştırmacı tarafından üç tane gözlem yapılmıştır. Bu gözlemlerden ilkinde video kamera kullanılmış ve bu gözlem sırasında öğrenciler de araştırma ve araştırmacı hakkında bilgilendirilmiştir.

İkinci aşamada ise ders öğretmenin tavsiyeleri dikkate alınarak araştırmacı tarafından beş öğrenci seçilmiştir. Görüşme için seçilen öğrencilerle, daha önce araştırmacı tarafından, araştırma sorusunun kapsamı dikkate alınarak hazırlanan görüşme formu ile birer görüşme yapılmıştır. $\mathrm{Bu}$ görüşmelerde öğrencilere Maple'ı ders dışında kullanıp kullanmadıkları, kullanıyorlarsa hangi derslerde nasıl kullandıkları, dersin işlenişi, Maple'da bir soruyu çözemeye nasıl başladıkları, Maple'ın en sık kullandıkları özellikleri, komutları ve programları yazarken nelere dikkat ettikleri ve Maple'da problem çözmenin onlara kolay ve zor gelen yanları hakkında sorular sorulmuştur. Her bir öğrenciyle yapılan görüşmelerin ses kaydı alınmış; ayrıca görüşmelerde verilen cevaplara ilişkin araştırmacı notları da veri olarak kaydedilmiştir. Veri toplama sürecinin ilk iki aşamasında (gözlem ve yarı yapılandırılmış görüşme) toplanan veriler araştırmaya temel veri kaynağ1 olacak olan klinik görüşmeler için kullanılacak problemi ve klinik görüşmeye katılacak öğrencileri belirlemek için kullanılmıştır.

Veri toplama sürecinin son aşaması olarak da bu öğrencilerden üçüyle Selin, Dilek ve Uğur- birer klinik görüşme yapılmıştır. Klinik görüşme, Piaget tarafından, öğrencilerin düşüncelerindeki zenginliği keşfetmek, temel aktivitelerini yakalamak ve bilişsel beceriyi değerlendirmek için geliştirilen ve matematik eğitiminde oldukça sık kullanılan bir yöntemdir (Baki, Karataş ve Güven, 2002).

$\mathrm{Bu}$ görüşmede öğrencilere, Maple'da çözmeleri istenen iki aşamalı bir problem sorulmuş ve görüşmelerin görüntü kaydı alınmıştır. Görüşme öncesinde de öğrencilere, araştırmacı tarafindan görüşmenin içeriği ve neler yapmaları gerektiği anlatılmıştır. Her bir öğrenciye, araştırmacı için önemli olanın, soruyu çözüp çözememeleri değil, bu soruları çözerken neler düşündükleri ve neler yaptıkları olduğu açılanmıştır. $\mathrm{Bu}$ yüzden problemleri çözerken mümkün olduğunca ne yaptıklarını açıklamaları istenmiştir. Bazı öğrencilerin bu açıklamaya rağmen sık sık sessiz kalmaları üzerine, araştırmacı tarafından ne düşündüklerini söylemeleri konusunda sonda soruları kullanılarak teşvik edilmişlerdir. 


\section{Verilerin Analizi}

Veri toplama süreci bittikten sonra, görüntü ve ses kaydı alınan görüşme ve gözlemler araştırmacı tarafindan bilgisayar ortamına aktarılmıştır. Verilerin analizi Nvivo7 programında yapılmış ve analiz yöntemi olarak içerik analizi (Strauss \& Corbin, 1990) kullanılmıştır.

Analiz süreci üç aşamada gerçekleşmiştir. Öncelikle görüşme ve gözlem kayıtları araştırmacı tarafindan yazılı metne çevrilmiş, birkaç defa okunmuş ve kodlamaları yapılmıştır. Bu kodlamalar yapılırken, öğrencilerin problem çözmede kullandığı stratejileri ortaya çıkaracak veriler göz önünde bulundurulmuştur. Analiz edilen veriler arasında araştırmacının görüşme ve gözlemler sırasındaki notları da bulunmaktadır. Fakat araştırmacı notları kodlamaya dâhil edilmemiş, bu notlardan araştırma konusuyla ilgili sonuç ve tartışma bölümünde yararlanılmıştır.

Kodlamalar yapıldıktan sonra, aynı dersi takip eden başka bir gözlemcinin kodlamalar konusunda görüşleri alınmış; daha sonra da bu görüşler doğrultusunda kategoriler ve temalar belirlenmiştir.

\section{BULGULAR}

Maple ortamında öğrencilerin problem çözme stratejileri, problemin analizi, problemin çözümü ve kontrol olmak üzere üç aşamada incelenmiştir. $\mathrm{Bu}$ aşamaların her birinde öğrenciler tarafindan kullanılan stratejilerin birbirleriyle olan ilişkileri dikkate alınarak ifade edilmiştir.

\section{Problemin Analizi}

$\mathrm{Bu}$ aşama, öğrencilerin çözüme başlamadan önce yapmış oldukları uygulamaları içeren kısım olarak karşımıza çıkmaktadır. Dolayısıyla problemlerin çözümü için ilk basamağı oluşturmaktadır.

Klinik görüşme yapılan katılımcıların hepsinin problemle karşılaştıklarında öncelikle soruyu okudukları (bir veya birkaç defa), ardından da problem durumunu ifade edecek bir şekil çizdikleri gözlemlenmiştir. Bu şekiller de Şekil 2a), b), c)' de görüldüğü gibidir.

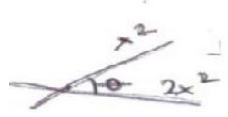

Şekil 2a)

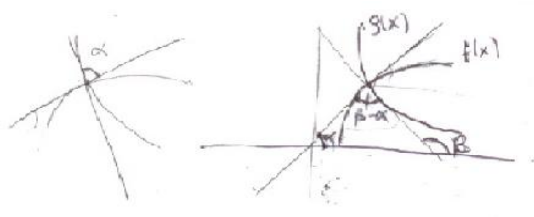

Şekil 2b)

(Selin'in çizimleri)

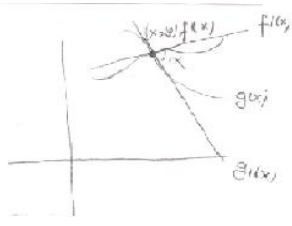

Şekil 2c)

(Uğur'un çizimi) 
Katılımcıların bu davranışı görselleştirme olarak kodlanmıştır. Selin soruyu okuduktan sonra şunları söylemiştir:

S: Önce bu kesiştikleri noktayı bulmam gerekiyor. Önce bir çizeyim. (K.G $G^{l}$ Selin)

Soruya ilişkin çizim yapıldıktan sonra öğrenciler, ne yapacaklarını zihinlerinde tasarlamaya başlamış; bunu yaparken de bazı öğrenciler bir süre sessiz kalmıştır. Araştırmacı tarafindan bu sessizliğe bir süre izin verilmiş; ardından öğrencilere, bu süre içinde ne düşündükleri sorulmuştur. Öğrenciler, sessiz kaldıkları sürede kendilerine problemin çözümü için nelerin gerekli olduğu ve bunları nasıl kullanacaklarını düşündüklerini ifade etmişlerdir.

S: Önce bu doğruların... Hımm... Bu eğrilerin türevi bu doğruların eğimine eşit oluyordu. $\mathrm{Bu}$ eğrilerin türevini alıp buradaki doğruları oluşturabilirim. (KG: Selin)

U: İki tane eğri olacak. Bir tanesi $\mathrm{f}(\mathrm{x})$, diğeri $\mathrm{g}(\mathrm{x})$ şeklinde. Ve bu iki eğri bir noktada kesişecek... Bunlar arasında kalan alfa açısını soruyor. Şu doğrunun denkleminin bulup (Yaptı̆̆ çizim üzerindeki doğrular üzerinde konuşuyor) bu doğrunun denklemini bulabiliriz. $\mathrm{y}=\mathrm{f}(\mathrm{x})$ de $\mathrm{y}$ 'nin türevini alırsam ve $\mathrm{x}_{\mathrm{o}}{ }^{1}$ yerine koyarsam elde ettiğimiz şey mi olacak? Burdan eğimi bulabiliriz. Diğeri için... Diğeri için de eğimi elde edebiliriz. İki doğru arasındaki açı trigonometrideki tan(a-b)' den çıkıyordu. (KG: Ŭgur)

$\mathrm{Bu}$ aşamada meydana gelen zihinsel model oluşturma süreci aslında problemin çözümüne geçilen ikinci aşamadaki ayrıştırma sadeleştirme basamağına benziyor gibi görünebilir. Fakat bir takım özellikleri ile ayrıştırma-sadeleştirme basamağından farklılık göstermektedir. Bu aşamada öğrenci, yapacaklarını zihninde tasarlarken, henüz neyi, hangi sırada yapacağını bilmemekte; sadece kendisine gerekli olabilecek matematiksel bilgileri ve maple komutlarını düşünmektedir. Ayrıştırma-sadeleștirme basamağında ise yapacaklarını sırasıyla parçalar halinde yazacaktır.

Birinci aşamanın son basamağında ise öğrenciler, zihinlerinde tasarladıkları ifadeleri bilgisayar ortamına nasıl aktarabileceklerini düşünmektedirler.

${ }^{1}$ KG: Klinik Görüşme 
A: Sen problemleri nasıl çözüyorsun?

U: ... Önce basit bir şekilde kalemle bir iki aşamada biz bunu daha önce analizde daha önceki derslerde ne şekilde kullanıyorduk, daha sonra bunu ne şekilde hangi komutlarla aktarabilirim diye bakıyorum. $\left(G^{2}: U \breve{g} u r\right)$

S: Problemin çözümünü kafamda tasarlamaya çalışıyorum. O problemin çözüm yolunu kendi kafamda tasarladıktan sonra, komutlarla çözmeye çalışıyorum. (G: Selin)

\section{Problemin Çözümü}

$\mathrm{Bu}$ aşama, problemin çözülmeye başlandığı kısım olarak karşımıza çıkmaktadır. Öğrenciler artık ne yapacaklarını zihinlerinde tasarladıkları için problemin çözümüne geçmişlerdir. Çözüm için birden fazla strateji bir arada kullanılmıştır. Bu stratejilerden ayrıştırma-sadeleştirme ve döngüsel olmayan strateji her üç katılımcı tarafindan, benzer problem bulma Dilek ve Uğur tarafından, deneme yanılma Uğur ve Selin tarafindan, araç amaç analizi ise sadece Uğur tarafından kullanılmıştır.

Ayrıştırma-sadeleştirme, probleme başlama stratejisi olarak her üç katılımcı tarafından kullanımı şöyle olmuştur:

S: Bize gerekli olan tek şey, Hımm... $\mathrm{f}(\mathrm{x})^{\prime}$ 'in eğimini bulduğumuzda $\tan (\alpha)$ y1 bulmuş oluyoruz; $\mathrm{g}(\mathrm{x})^{\prime}$ in türevini bulduğumuzda $\tan (\beta)$ 'yı bulmuş oluyoruz. Bizden $\tan (\alpha-\beta)^{\prime} y 1$ istemişti zaten. $\tan (\beta-\alpha)$ buradaki formüle eşit zaten. (KG: Selin)

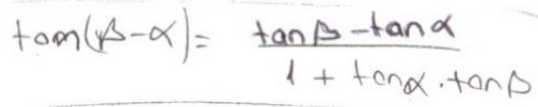

Şekil 3

D: Hımm... Tamam. Şimdi Maple'da kullanabileceğim tanımlamaları yazıyorum.

${ }^{2} \mathrm{G}$ : Görüşme 


$$
\begin{aligned}
& m_{1}=f^{\prime}(x) \\
& m_{2}=f^{\prime}(x)
\end{aligned}
$$

\section{Sekil 4}

$\mathrm{Bu}$ iki doğrunun eğimleri... Bu noktadaki eğimleri lazımmış. Tamam, prosedür'e geçeyim. Şimdi öncelikle bunu $\left(m_{l}=f^{\prime}(x), m_{2}=g^{\prime}(x)\right)$ "diff" olarak tanımlayacağım. Daha sonra içinde "subs" kullanacağım. Sonra da şu eşitliği yazacağım. (KG: Dilek)

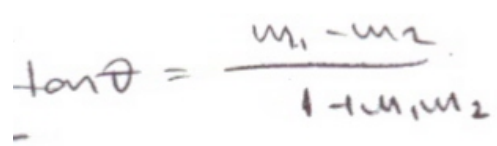

Şekil 5

Görüldüğü gibi ilk aşamada öğrenciler kendilerine nelerin gerekli olabileceğini zihinlerinde tasarlamışlar, daha sonra bunları nasıl bulabileceklerini ve hangi sıraya göre yazacaklarını problemi parçalara ayırarak tespit etmişlerdir. Bu davranışlar araştırmacı tarafından ayrıştırmasadeleştirme stratejisinin bir parçası olarak kabul edilmiştir.

$\mathrm{Bu}$ aşamada kullanılan bir diğer strateji de araç amaç analizi olmuştur. Daha önce de belirtildiği gibi araç amaç analizi mevcut durumla problemin amacı arasındaki farkı en aza indirme stratejilerini içermektedir (Reed, 2007). Mayer (1983)'e göre araç amaç analizini kullanan bir problem çözücü, içinde bulunduğu durumu çözmek için amacını belirlemeli, eğer bu amaca ulaşamıyorsa alt amaçlar belirleyerek asıl amacına ulaşmasını engelleyen durumları ortadan kaldırmalıdır. Dolayısıyla problem çözücü her zaman, amacının, çözüme ulaşmasını engelleyen durumların ve bunları ortadan kaldıracak işlemlerin ne olduğu sorularını kendine yöneltmelidir (Simon 1969, s. 112, akt. Mayer, 1983). Öğrenciler tarafindan bu stratejinin kullanımı şöyle ifade edilmiştir.

U: Prosedür'ü yazmaya başlasak şuradan... "kesim" diyelim. Bize $\mathrm{f}(\mathrm{x})$ ve $\mathrm{g}(\mathrm{x}))^{\prime} \mathrm{i}$ bir de $\left(\mathrm{x}_{0}, \mathrm{y}_{\mathrm{o}}\right)^{\prime} 1$ verecek. (soruyu tekrar okuduktan sonra $x_{o}$ ve $y_{o}$ noktaların kendi bulmast gerektiğini anladı.) $\mathrm{O}$ zaman bu iki eğrinin hangi noktada kesiştiklerini 
bulmam gerekiyor. Bunu bulmak için ne yapmam gerekiyor. Bu denklem sistemini çözmem gerekiyor $\mathrm{f}(\mathrm{x})$ ve $\mathrm{g}(\mathrm{x})$ e göre.

U: Şimdi $\mathrm{m}_{1}$ 'i bulacağız yerine koyma işlemi yapacağız. "subs " yerine koy, ne koy, $\mathrm{x}$ yerine $\mathrm{x}_{0}$ koy, nerede koy fnin türevinde koy. (KG: Ŭgur)

...

A: Ne düşündün?

U: Soruyu tanımaya çalıştım. Sonuç olarak bizden ne istediğini bulmaya çalıştım. Ona ulaşırken bizden istediği şey $\tan (\alpha)$. Bunu da $m_{1}$ ve $m_{2}$ den bulabiliriz. $m_{1}$ ve $m_{2}$ 'yi bulabilmemiz için de... $\mathrm{f}(\mathrm{x})$ için $\mathrm{m}_{1}{ }^{\prime} \mathrm{i}, \mathrm{g}(\mathrm{x})$ için de $\mathrm{m}_{2}$ 'yi bulabileceğimiz için nerden, neyi ne şekilde bulabileceğimizi düşündüm önce. ( $K G$ : Uğur)

Problemi çözmeye başladıktan sonra öğrenciler, içinde bulundukları basamakta yapacaklarına, bir önceki basamağa dönmeye neden olup olmayacağını düşünerek karar vermişler, geri dönmelerine neden olacak davranışlardan kaçınmışlardır. Daha önce alanyazında da verildiği gibi bu kullanım döngüsel olmayan strateji tanımı ile örtüşmektedir. Örneğin;

S: Hımm... $\mathrm{x}$ değerini bulduğum zaman, onu kullanmam için ne yapmam gerekiyor, onu düşünemedim. Hımm... Listeye aktarabilirim. Öyle yapmak yerine şöyle denemek istiyorum önce. Şunu $(\mathrm{a}:=\operatorname{diff}(\mathrm{A}, \mathrm{x}))$ üste alırsam aslında... Ben bunu $\mathrm{x}$ 'e göre çözüp x'i de bu şekilde $(\mathrm{x}=$ solve $(\mathrm{A}=\mathrm{B}, \mathrm{x}))$ tanımlarsam 'a='dediğim zaman çıkar diye düşünüyorum. $(K G$ : Selin $)$

D: Şimdi $\mathrm{m}_{1}$ noktasını, $\mathrm{f}$ fonksiyonunun $\mathrm{x}^{\prime} \mathrm{e}$ göre türevi olarak tanımladım. Yalnız bundan önce yerine $\mathrm{x}_{\mathrm{o}}$ ve $\mathrm{y}_{\mathrm{o}}$ noktasını da koymalıyım. Şu anda $\left(\mathrm{x}_{0}, \mathrm{y}_{\mathrm{o}}\right)$ noktasını yerleştiriyorum. $\mathrm{y}_{0}{ }^{1}$ koymama gerek var $m ı$ diye düşünüyorum da... Hımm... Zaten $x$ cinsinden bir fonksiyon, o zaman y'ye gerek yoktur. Ben soruyu yanlış $\mathrm{m} ı$ anladım. Tamam, bunları kesiştiriyoruz, bunlar $\left(\mathrm{x}_{0}\right.$, $\mathrm{y}_{\mathrm{o}}$ ) gibi bir noktada kesişiyor da şimdi bu iki doğruların eğimi lazım bana. Tamam eğimleri bulurum da eğimleri bulduktan sonra $\mathrm{m} 1\left(\mathrm{x}_{0}, \mathrm{y}_{\mathrm{o}}\right)^{\prime} 1$ yerine koyacağım. (KG: Dilek) 
$\mathrm{U}: \mathrm{x}_{0}:=\left(\right.$ solve $(\mathrm{f}(\mathrm{x})-\mathrm{g}(\mathrm{x})=0, \mathrm{x}), \mathrm{x}_{0}$ olacak ama burdan iki değer gelebilir mi diye düşünüyorum... İkinci dereceden olursa... (Soruyu tekrar okuduğunda iki nokta bulunsa bile bu noktalardan herhangi birini alabileceğine karar verdi) Bu iki nokta olsun. Biz iki nokta gibi düşünelim ve bu yüzden bunu liste biçiminde tanımlayalım. ( $K G: U \breve{g} u r)$

Bazen yaptıkları işlemler öğrencilere çok soyut gelmiştir. Programın yazdıkları kısmının nasıl çalışacağını sayısal bir örnekle görmek istedikleri gözlemlenmiştir. Bunun için soruda belirtilen fonksiyon yerine kendileri fonksiyonlar atayıp, programda yapılan işlemleri tekrarlamışlardır. Uğur bu işlemi programı yazarken, Dilek hem programı yazarken hem de programı yazdıktan sonra Maple'da çalıştırıp hata verdiğini gördüğü zaman yapmıştır. $\mathrm{Bu}$ gözlemler de araştırmacı tarafindan benzer problem bulma stratejisi olarak kodlanmıştır.

D: Tamam eğimleri bulurum da eğimleri bulduktan sonra $\mathrm{ml}$ $\left(\mathrm{x}_{0}, \mathrm{y}_{\mathrm{o}}\right)^{\prime} 1$ yerine koyacağım. (Yazdlklarına tekrar baktı. Çizdiği şekil üzerindeki ĕgrilere birer fonksiyon atadı ve...)

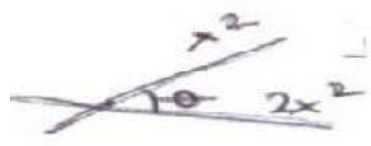

Şekil 6

Tamam, $y_{0}$ lazım değil. Çünkü fonksiyonlarım sadece x'e bağlı. Türevlerini aldığımda $x$ 'li ifadeler çıkıyor. O yüzden de $\mathrm{x}_{\mathrm{o}}$ '1 yerine koymam gerekiyor diye düşündüm. (KG: Dilek)

U: Acaba şöyle yapsak daha kolay olur mu? (İşlem yaptı̆̆ kâğıdın bir kenarına iki tane fonksiyon yazdı. Bunları ortak çözdü. Ve fonksiyonları ikinci dereceden yazdlğı için iki tane kök bulabileceğini fark etti) 

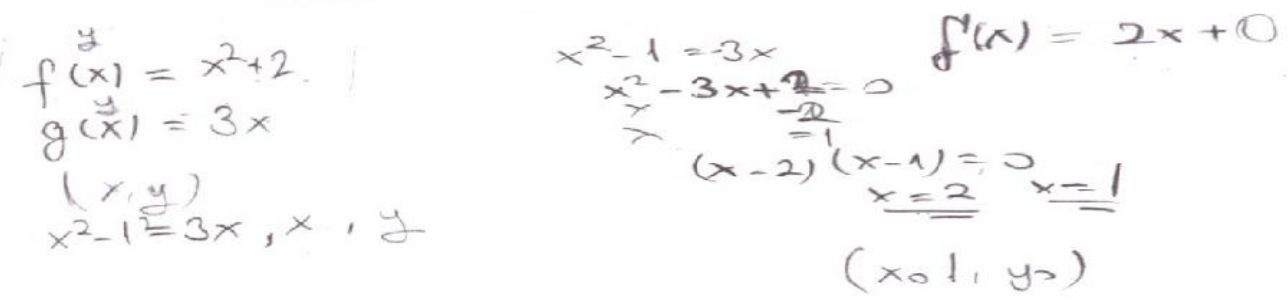

Şekil 7

Sayısal düşünürsek sonra genele aktarabilir miyiz diye düşünüyorum da...

U: Onu düşünürken de kolay olsun diye sayısal, bilindik bir şeyin üstünden gitmeye çalıştım. Burada $\mathrm{x}^{2}$ verdiğim için iki tane kök geldi. Bu iki olabilir, üç olabilir. Bu yüzden liste düşündüm orda. (KG: Ŭgur)

\section{Kontrol}

$\mathrm{Bu}$ aşamaya gelinceye kadar öğrencilerin her biri, çeşitli problem çözme stratejileri uygulamış ve probleme çözüm olarak önerdikleri prosedürleri yazmışlardır. Bu aşamada ise yazdıkları prosedürü bilgisayara girmişler ve çalışıp çalışmadığını kontrol etmişlerdir. Klinik görüşme yapılan tüm öğrencilerin programlarının hata verdiği gözlenmiştir. $\mathrm{Bu}$ hatalarla karşılaştıklarında yaptıkları ilk şey programı kontrol etmek olmuş, bunun için yazdıkları prosedürü tekrar okumuşlardır. Eğer sorun programdaki komutların yazımından kaynaklanan bir hata ise bunları o anda düzeltmişler, fakat problemin çözümüyle ilgili bir hata olduğunu düşünmüşlerse problemi çözme sürecine tekrar dönmüşler ve yaptıkları hataları düzeltecek diğer stratejileri işe koşmuşlardır.

Klinik görüşme yapılan üç katılımcının da programlarının hata vermesine rağmen, Dilek ve Selin'in hatayı bulmak için kullandıkları kontrol uygulamaları, problemlerin doğru sonucuna ulaşmalarını sağlamıştır. Dilek yazdığı prosedüre ilişkin hata mesajında iki tane sonuç beklendiğini ögrenmiş ve neden iki sonuç bulabileceğine dair düşünmeye başlamıştır. İlk tahminin yanlış olduğuna yazdığı prosedürün basamaklarını inceledikten sonra karar vermiş, ardından fonksiyonların iki noktada kesişebileceğini fark etmiştir. Bunun için soruyu tekrar okumuş, soruda verilen fonksiyonları 
ortak çözmüş ve hatanın iki kesişim noktasından kaynakladığından emin olduktan sonra yeni duruma uygun çözümü düşünmeye başlamıştır.

D: Hımm... Bir tane sonuç bekleniyormuş iki tane çıkmış. Bir tane sonuç niye bekliyormuş ki... Hımm... Sanırım şu anda dar açıyla geniş açıyı buldu ya... Hata mesajına göre iki sonuç bulmuş. Biz bir sonuç bekliyorduk. İki sonuç bulmasını da dar açıyla geniş açıya bağladım. (Son olarak

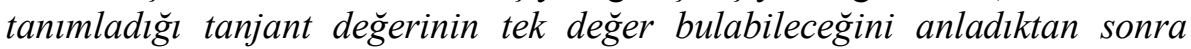
tekrar düşünmeye başladl...)

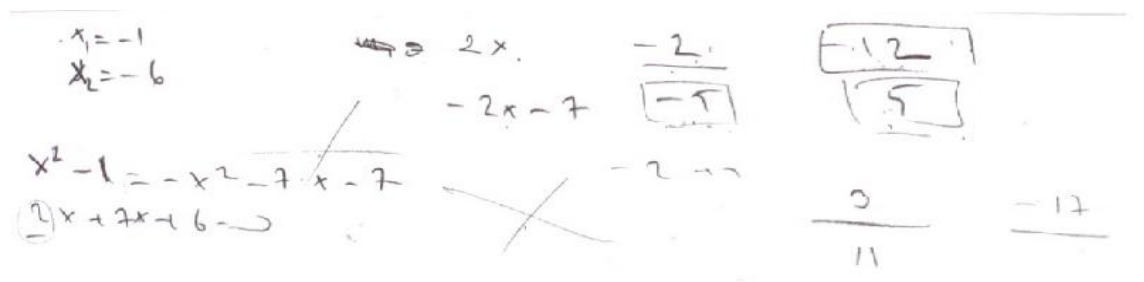

Şekil 8

D: Hımm... O zaman kesişim noktası $\mathrm{m}$ iki tane? (Bilgisayar ekranına baktı. Çözüm kâğıdına baktı. Soruyu tekrar okudu.) Eveeet, iki kesişim noktası var. Denediğimiz fonksiyonların çözümünden iki tane $\mathrm{x}$ noktası buluyor. Bunu da nasıl gösteririz... Liste mi yapayım o zaman acaba...? Liste yapsam. (KG: Dilek)

Selin de programı hata verdikten sonra yazım ile ilgili bir hata olduğunu düşünmüş, yazdıklarını tek tek kontrol etmiştir. Yazım yanlışı olmadığına karar verdikten sonra sorunun nerden kaynaklanabileceğini düşünmeye başlamıştır. Araştırmacı tarafından yöneltilen sorulardan sonra böyle bir durumla karşılaştığında daha önce ne yaptığını hatırlamış ve uygulamıştır. Selin'in programındaki hatayı bulmak için kullandığı strateji ise ayrıştırma sadeleştirme olarak kodlanmıştır.

A: Bu hatayla, sen kendi başına soruyu çözerken karşılaşsaydın ne yapardın?

S: Kendi başıma ödev yaparken bir hatayla karşılaştığım zaman işlemleri basamak basamak yaparım, prosedür olarak değil de... (Daha sonra prosedür içindeki işlemleri, prosedür dışında parçalara ayırdı ve hatasını buldu.) 
>restart;

$>\mathbf{A}:=\mathbf{x}^{\wedge} \mathbf{2 - 1} ; A:=x^{2}-1$

$>\mathbf{B}:=-\mathbf{x}^{\wedge} 2-7 * \mathbf{x}-7 ; B:=-x^{2}-7 x-7$

$>\mathbf{a}:=\operatorname{diff}(\mathbf{A}, \mathbf{x}) ; a:=2 x$

$>\mathbf{b}:=\operatorname{diff}(\mathbf{B}, \mathbf{x}) ; b:=-2 x-7$

$>\mathbf{h}:=[\operatorname{solve}(\mathbf{A}=\mathbf{B}, \mathbf{x})] ; h:=\left[\frac{-3}{2},-2\right]$

$>\mathbf{t}:=(\mathbf{b}-\mathbf{a}) /(\mathbf{1}+\mathbf{a} * \mathbf{b}) t:=\frac{-4 x-7}{1+2 x(-2 x-7)}$

$>\mathbf{t} 1:=\operatorname{subs}(\mathbf{x}=\mathbf{h}[1], \mathbf{t}) ; t 1:=\frac{-1}{13}$

$>\mathbf{t} 2:=\operatorname{subs}(\mathbf{x}=\mathbf{h}[2], \mathbf{t}) ; t 2:=\frac{1}{13}$

S: Birden fazla değer buluyormuş... İki noktada kesişiyormuş. O zaman bunları (kökleri) bir listeye atmam gerekecek... Bir de öyle deneyim. Bir tane $\mathrm{x}_{1}$, bir tane de $\mathrm{x}_{2}$ için yapmam gerecek. Ama o zaman üst tarafı da değiştirmem gerekiyor.(KG: Selin)

Uğur da programı hata verdikten sonra yazım yanlışı olup olmadığını anlamak için prosedürü tekrar okumuş, yazımda bir hata olmadığına karar verdikten sonra çözümüyle ilgili bir hata olup olmadığını araştırmaya başlamış, fakat doğru sonuca ulaşamamıştır.

U: Hata ile karşılaştığımda ilk düşündüğüm şey acaba komutun yazımı $\mathrm{m} ı$ yanlış, aralardaki virgüller mi yoksa sondaki noktalı virgül mü eksik diye düşündüm. ( $K G: U \check{g} u r$ )

Bazı durumlarda ise öğrenciler, karşılaştıkları hatanın nedeni hakkında hiçbir fikir üretememişlerdir. Bu durumda ise programın nerede hata vermiş olabileceğini tahmin etme yoluna gitmişler ve programda, herhangi bir dayanağı olmayan hatta bazı durumlarda derste öğrendikleriyle çelişen değişiklikler yapmışlardır. Bu uygulamalar da deneme-yanılma stratejisi olarak tanımlanmıştır.

U: Buradaki parantezi tanımadı, acaba $\mathrm{y}_{1}, \mathrm{y}_{2}$ mi desem. Veya $f(x)$ 'in yerine $A, g(x)$ 'in yerine $B$ girelim. 
U: Şu anda hiçbir şey düşünemiyorum çünkü böyle bir şey hiç karşıma çıkmamıştı... Acaba yanlış mı girdik? Aralarda virgül olacak şekilde ve sonda noktalı virgül olacak şekilde girmemiz gerekiyordu. Acaba local'leri kaldırsak ne olur!... (KG: Ŭgur)

A: Ne düşünüyorsun? Aklından ne geçiyor?

S: Hiç bir şey geçmiyor. Doğru olduğunu sanmıştım ama değilmiş. Şu "x"e farklı bir şey versem, şu "x" ile mi karışt1 acaba diye! (KG: Selin)

Öğrencilerin bilgisayar cebiri sistemlerinden biri olan Maple ortamındaki problem çözme stratejilerini kullanımları Şekil 9'daki gibidir.

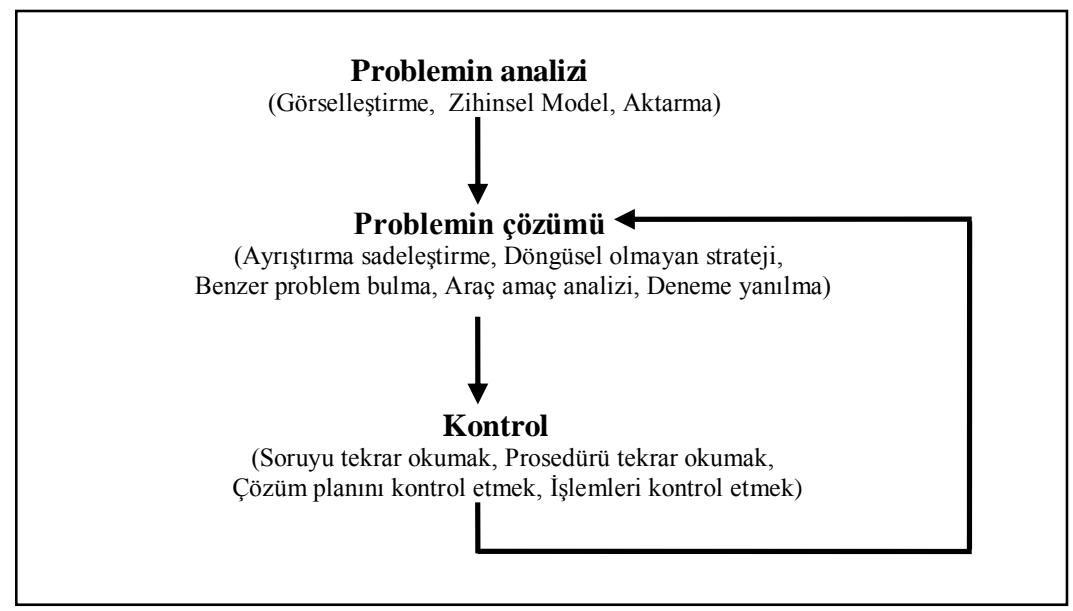

Şekil 9: Maple ortamında problem çözme stratejilerinin kullanımı.

\section{SONUÇ VE TARTIŞMA}

$\mathrm{Bu}$ çalışmada, üniversite öğrencilerin Maple'da problem çözerken kullandıkları stratejiler incelenmiştir. Araştırma sonuçlarına göre öğrencilerin Maple'da problem çözerken en çok ayrıştırma sadeleştirme, benzer problem bulma, döngüsel olmayan strateji ve araç-amaç analizini kullandığ1 gözlemlenmiş̧tir. Çalışmaya katılan öğrencilerin tamamı, çözüm için tek strateji yerine problemin farklı aşamalarında farklı stratejiler kullanmışlardır. 
Çalışmada, öğrencilerin problem çözme stratejileri için üç aşama olduğu ortaya konmuştur. $\mathrm{Bu}$ aşamalardan ilkinde, aktarma basamağ 1 öğrenciler tarafindan sözel olarak çok fazla ifade edilmemiş, araştırmacının soruları sayesinde bu basamak ortaya çıkarılmıştır. Öğrenciler bu basamakta, kurdukları zihinsel modeli bilgisayar ortamina nasıl aktaracaklarını düşünmektedirler. Bunun sözel olarak çok fazla ifade bulmamasının sebebi, araştırmada kullanılan sorunun çok karmaşık olmaması veya öğrenci aklında çok hızlı gerçekleşmesi olarak düşünülebilir.

Araştırmanın başlangıcında, veri toplama yöntemi olarak çalışmaya katılan öğrencilerle birer görüşme yapılmıştır. Bu görüşmelerde öğrencilerin tümü, Maple'ın en çok grafik çizme özelliğinden hoşlandıklarını veya bunu kullandıklarını belirtmişlerdir. Fakat öğrencilerden hiçbiri problemin ikinci aşamasında Maple'ın grafik çizdirme özelliğini kullandığı gözlenmemiştir. Bunun sebebi, problemin çözümünün veya grafiğinin Maple'ı kullanmayı düşündürecek zorlukta olmaması veya karşılaştıkları hatalara çözüm bulabilmeleri olabilir. Çünkü yine görüşmeler sırasında öğrenciler, Maple’1 daha çok karmaşık fonksiyonların çözümünde, grafiklerinin çiziminde veya yaptıklarını kontrol etmek için kullandıklarını belirtmişırerdir. Ancak soruda verilen eğrilerin ikinci dereceden olduğunu ve bu iki eğrinin ortak çözümünden iki kök geldiğini Selin ve Dilek bir süre fark edememiş, Dilek bunu programın verdiği hata mesajıyla, Selin ise problemi parçalara ayırma stratejisi sayesinde bulmuştur.

Klinik görüşme yapılan tüm öğrenciler sorunun çözümüne şekil çizerek başlama ihtiyacı hissetmişlerdir. Bunu yapmalarındaki en önemli sebep soruyu daha iyi anlamak ve soruyu bir şekille özetlemek olduğu söylenebilir. Selin bunu, " önce bir çizeyim” cümlesiyle ifade ederken, Dilek ve Uğur soruyu ikinci defa okuyuşlarında yaptıkları çizimlerle göstermişlerdir. Ayrıca problemlerin çözümü sırasında hatalarının sebebini anlamak, yaptıklarını kontrol etmek ve soruyu daha iyi anlamak için zaman zaman çizdikleri şekillere geri dönmüşlerdir. Alanyazın incelendiğinde de görsel ifadelerin problem çözme sırasında sıklıkla kullanıldığı görülmektedir (Diezmann \& English, 2001; Stylianou \& Silver, 2004; Rosengrant, Heuvelen \& Etkina, 2006; Nunokawa, 2006). Stylianou ve Silver (2004), uzmanların görsel ifadeleri problem uzayının niteliklerini keşfetmek, problem durumunu daha iyi anlamak, çözüm planını yönlendirmek ve geliştirmek amacıyla acemilere oranla daha sik kullandıklarını belirtmektedir. Rosengrant, Heuvelen ve Etkina (2006) ise öğrencilerin bir problemin çözümüne ilişkin çizdikleri diyagramların doğruluğunun, problemin çözülme olasılığını artırdığını söylemektedir. Öğrenciler de çizim yaparken soruya birkaç defa tekrar dönerek, probleme uygun çizim yapıp 
yapamadıklarını kontrol etmişlerdir. Bunun yanında öğrencilerin farklı gösterimler arasında hareket etmesi, çözüme ulaşmalarını engelleyen zorlukların üstesinden gelmek için kullandıkları bir stratejidir (Waters, 2003).

Öğrenciler, yazdıkları programların doğruluğunu bilgisayarda kontrol etmiş ve klinik görüşmeye katılan tüm öğrencilerin programları hata vermiştir. Bu hataları düzeltmek için öğrencilerin kullandıkları kontrol stratejileri soruyu tekrar okumak, prosedürü tekrar okumak, çözüm için uygulanan planı kontrol etmek ve işlemleri kontrol etmek şeklinde olmuştur. Kontrol stratejilerinin hepsi, tüm katılımcılar tarafindan kullanılmıştır. Araştırmaya katılan öğrencilerin tamamı, hata ile karşıllaştıkları ilk anda yazdıkları prosedürü tekrar gözden geçirmiş, yazım yanlışı veya eksiği olup olmadığına bakmış, daha sonra da çözüm için uygulanan planı kontrol etmişlerdir. Dilek programın verdiği hata mesajını sebebini yanlış yorumlamış; fakat problemi somutlaştırmak için problemin ikinci aşaması üzerinden düşünüp yaptıklarını kontrol ettiğinde doğru sonuca ulaşmıştır. Selin ise hata kaynağına ulaşmak için stratejisini değiştirmiş, çözümünü parçalara ayırarak prosedür dışında her bir basamağı tek tek kontrol etmiş ve hatasını bulmuştur. Uğur ise prosedürünü kontrol ettikten sonra çözüm için uyguladığ1 planının doğru olduğunu düşünmüş, programın neden hata verdiğini anlayamamış ve çözüm için kullandığı stratejiyi değiştirmiştir. Fakat karşılaştığ durumun nedenini tahmin edemediği için hatasını düzeltmek adına yaptıkları, daha çok deneme yanılma uygulamaları olmuştur. Çünkü yazdığı prosedür üzerinde, derslerde öğrendiklerine uymayan değişiklikler yapmış, daha sonra "böyle bir durumla daha önce hiç karşılaşmadığını ve ne yapabileceği hakkında hiçbir fikrinin bulunmadığını" söyleyerek bu durumu kendi de kabul etmiştir. Uğur'un strateji değişiminde ortaya çıkan bu fark English (1992) ve Schauble (1990) (akt. Harmon ve Morse, 1995)'in çalışmalarındaki, problemin zorluk düzeyi arttıkça, çocukların gelişmiş stratejilerden vazgeçip daha az gelişmiş stratejilere yöneldiği bulgularıyla örtüşmektedir. Harmon ve Morse (1995)'a göre bu gerileme, çözümü daha karmaşık durumlara uygularken, yetersiz anlama veya bilgiden kaynaklanmaktadır. Uğur'un da karşılaştığı hatanın nedenini bulamaması, çözüm üretmesini güçleştirmiş ve daha yararsız stratejilere yönelmesine sebep olmuştur. Görüldügü gibi kontrol aşamasından sonra seçilen stratejinin gelişmişliği ile doğru sonuca ulaşma arasında yüksek bir ilişki olduğu söylenebilir. Uğur'un strateji değiştirerek deneme yanılma stratejini kullanması, doğru sonuca ulaşmasını engellemiştir. Oysa Selin'in seçtiği, problemi basamaklarına ayırma ve her bir basamağın doğruluğunu kontrol etme ile Dilek'in problemin ikinci aşamasını benzer problem olarak kullanması hatalarını bulmalarında önemli rol oynamıştır. 
Teknolojinin bir getirisi olan bilgisayarların sürekli yenilenmesi ve gelişmesi eğitim sürecinin de içine fazlasıyla girmesine sebep olmuştur. Son yıllarda bilgisayar cebir sistemleri gibi yazılımlar da hem matematik hem de matematik eğitimi içindeki yeri hızla artmaktadır. Her ne kadar bazı araştırmacılar bu gelişmenin olumsuz etkilerinin de olabileceğini öne sürseler de bilgisayarların uygun kullanımı, öğrencilere matematiğin birçok alanında kolaylık sağlayacağı, kağıt kalemin sağlayamayacağı keşif olanakları sunacağı ve aslında birer problem çözme ortamı olduğu da bir gerçektir. Bu gerçek göz önüne alındığında, öğrencilerin bu ortamda daha iyi çalışmaları ve daha verimli stratejiler geliştirebilmeleri için matematik ve bilgisayar cebir sistemleri gibi yazılımların bütünleştirildiği öğretim programları düzenlenmelidir. $\mathrm{Bu}$ öğretim programlarının başarıya ulaşabilmesi ise öğretmen adaylarının bu konuda deneyimli olmasına bağlıdır. Dolayısıyla üniversitelerdeki matematik öğretmeni yetiştirme programlarının da Maple gibi güncel yazılımlarla desteklenmesi faydalı olacaktır.

\section{KAYNAKLAR}

Aksoy, Y. (2007). "Türev Kavramının Öğretilmesinde Bilgisayar Cebiri Sistemlerinin Etkisi." Yayımlanmamış doktora tezi, Gazi Üniversitesi Eğitim Bilimleri Enstitüsü, Ankara.

Altun, M. (2000). “İlköğretimde Problem Çözeme Öğretimi.” Milli Eğitim Dergisi, 147.

Aktümen, M. (2007). "Belirli İntegral Kavramının Öğretiminde Bilgisayar Cebiri Sistemlerinin Etkisi." Yayımlanmamış doktora tezi, Gazi Üniversitesi Eğitim Bilimleri Enstitüsü, Ankara.

Arsham, H. \& Oblak, M. (1996). Matrix inversion: a computational algebra approach. International Journal of Mathematical Education in Science and Technology, 27(4), 599-605.

Baki, A., Karataş, İ. \& Güven, B. (16-18 Eylül 2002). Klinik Mülakat Yöntemi İle Problem Çözme Becerilerinin Değerlendirilmesi. V. Ulusal Fen Bilimleri ve Matematik Eğitimi Kongresinde sunulmuş bildiri, Ankara.

Boulter, D. R. \& Kirby, J. R. (1994). Identification of stratejies used in solving transformational geometry problems. Journal of Educational Research, 87(5), 298-303. 
Brody, J. \& Rosenfield, S. (1996). Problem posing/solving and linear algebra. International Journal of Mathematical Education in Science and Technology, 27(1), 103-121.

Bruning, R. H., Schraw, G. J.\& Roning, R.R. (1995). Cognitive Physchology and Instruction $\left(2^{\text {nd }}\right.$ Ed. $)$. Prentice-Hall:New Jersey

Bulut, M. (2009). “İşbirliğine Dayalı Yapılandırmacı Öğrenme Ortamlarında Kullanılan Bilgisayar Cebir Sistemlerinin Matematiksel Düşünme, Öğrenci Başarısına Ve Tutumuna Etkisi." Yayımlanmamış doktora tezi, Gazi Üniversitesi Eğitim Bilimleri Enstitüsü, Ankara.

Carvalho, M. J.\& D'Agostino S. (2001).A MAPLE program for calculations with Schur functions. Computer Physics Communications, 141(2), 282295.

Cheung, Y.L. (1996). Learning number theory with a computer algebra system. International Journal of Mathematical Education, 27(3), 379385 .

Crocker, D. A. (1991). "A qualitative study of interactions, concept development and problem-solving in a calculus class immersed in the computer algebra system Mathematica(TM)." Yayımlanmamış doktora tezi, The Ohio State University.

Davies, S.P. (2000). Memory and planning processes in solutions to wellstructured problems. The Quarterly Journal of Experimental Psychology, 53A(3), 896-927.

Diezmann, C, M. \& English, L. D. (2001). Promoting the use of diagrams as tools for thinking. In A. A. Cuoco \& F.R. Curcio (Eds.), The roles of representation in school mathematics (pp. 77-89). Reston, VA: NCTM.

Gander, W. \& Gruntz, D. (1999). Derivation of Numerical Methods Using Computer Algebra. Society for Industrial and Applied Mathematics, 41(3), 577-593.

Gorgorió, N. (1998). Exploring the funtionalitly of visual and non-visual strategies in solving rotation problems. Educational Studies in Mathematics, 35, 207-231.

Ghusayni, B. (2005). Maple explortions, perfect numbers and Mersenne primes. International Journal of Mathematical Education in Science and Technology, 36(6), 643-654.

Hammouri, H. A. M. (2003). An Investigation of Undergraduates' Transformational Problem Solving Strategies: cognitive/metacognitive processes as predictors of holistic/analytic strategies. Assessment \& Evaluation in Higher Education, 28(6). 
Harmon, M., G. \& Morse, L.,W. (1995, Summer). Strategies and knowledge in problem solving: Results and implication for education. Education, $115,4,580-589$.

Houstis, E. N. (2003). "The Role of Problem Solving Environments in Engineering and Mathematics Education." Published in the Proceedings of the $6^{\text {th }}$ International Conference on "Technology in Mathematics Teaching".

Jonassen, D. H. (1997). Instructional Design Models for Well-Structured and Ill-Structured Problem-Solving Learning Outcomes. ETR\&D, 45, 1, 65-94.

Kabaca, T. (2006). "Limit Kavramının Öğretiminde Bilgisayar Cebiri Sistemlerinin Etkisi." Yayımlanmamış doktora tezi, Gazi Üniversitesi Eğitim Bilimleri Enstitüsü, Ankara.

Leinbach, C; Pountney, D. C. \& Etchells, T. (2002). Appropriate use of a CAS in the teaching and learning of mathematics. International Journal of Mathematical Education in Science \& Technology, 33, 1, 1-14.

Lu, J. \& Ye, Z. (2000). Application of CASs to iterative solution of nonlinear analysis of shallow conical shell. Computer Methods in Applied Mechanics and Engineering, 181, 1-3, 345-361.

McCoy, L. P. (1996). Computer-based mathematics learning. Journal of Research on Computing in Education, 28(4), 438-461.

MEB, Talim Terbiye Kurulu Başkanlığı (2005). Ortaöğretim Matematik Dersi Öğretim Programı. http://ttkb.meb.gov.tr/ogretmen/modules.php? name $=$ Downloads $\&$ dop $=$ viewdownload $\&$ cid $=75$ adresinden erişilmiştir.

Malloy, C. \& Jones, M. (1998). An investigation of African American students' mathematical problem solving, Journal for Research in Mathematics Education, 29(2), 143-164.

Mayer, R. E. (1983). Thinking, problem solving, congnition. New York: W.H. Freeman and Company

Nunokawa, K. (2006). Using drawings and generating information in mathematical Problem solving processes. Eurasia Journal of Mathematics, Science and Technology Education, 2, (3).

Patton, M. Q. (2002). Qualitative research and evaluation methods, Sage Publication: USA

Pierce, R., \& Stacey, K. (2001). Observations on Students' Responses to Learning in a CAS Environment. Mathematics Education Research Journal, 13(1), 28-46. 
Póyla, G.(1997). Nasıl Çözmeli?. (Çev. F. Halatçı). İstanbul: Sistem Yayınc1lık. (Özgün kitap 1945'de yayımland1.)

Pountney, D. C.; Leinbach, C. \& Etchells, T. (2002). The issue of appropriate assessment in the presence of a CAS. International Journal of Mathematical Education in Science \& Technology, 33, 1, 15-36.

Reed, S. K. (2007). Cognition: Theory and application. USA: Thomson Wadsworth

Rosengrant, D., Heuvelen, A. V.\& Etkina, E. (2006). "Case Study: Students' Use of Multiple Representations in Problem Solving." Paper presented at Physic Education Research Conference.

Srinivasan, V. K. (1997). Three perspective on the limit of a function. International Journal of Mathematical Education in Science and Technology, 28(2), 185-196.

Stenphens, L. J. \& Konvalina, J. (1998). The use of computer algebra software in teaching intermediate and college algebra. International Journal of Mathematical Education in Science and Technology, 30(4), 483-488.

Strauss, A. L \& Corbin, J. (1990). Basic of qualitative research: Grounded theory procedures and tecniques. Newbury Park, CA: Sage

Stylianou, D. A. \& Silver, E. A. (2004). The role of visual representations in advanced mathematical problem solving: An examination of expertnovice similarities and differences. Mahtematical Thinking and Learning, 6(4), 353-387.

Waters, M. S. (2003). "How and why students select, apply, and translate among mathematical representations in problem solving while learning algebra in a computer algebra system learning environment." Yayımlanmamış doktora tezi, Ohio University.

Weigand, H. G. \& Weller, H. (2001). Changes of working styles in a computer algebra environment - the case of functions. International Journal of Computers for Mathematical Learning, 6 .

Wilson, J. W., Fernandez, M. L., \& Hadaway, N. (1993). Mathematical problem solving. In P.S. Wilson (Eds.), Research ideas for the classroom: High school mathematics, New York, NY: Macmillian. 